\title{
Tracing the fate of phosphorus \\ fertilizer derived cadmium in soil- fertilizer-wheat systems using enriched stable isotope labeling
}

\author{
CHRISTOPH BRACHER ${ }^{1}$, EMMANUEL FROSSARD ${ }^{2}$, \\ MARTIN IMSENG ${ }^{1}$, MORITZ BIGALKE ${ }^{1}$ AND MATTHIAS \\ WIGGENHAUSER ${ }^{2}$ \\ ${ }^{1}$ University of Bern, Institute of Geography \\ ${ }^{2}$ ETH Zurich, Institute of Agricultural Sciences \\ Presenting Author: matthias.wiggenhauser@usys.ethz.ch
}

The application of mineral phosphorus (P) fertilizers represents a considerable input of the toxic heavy metal cadmium (Cd) into arable soils. Here, we investigated the fate of $\mathrm{P}$ fertilizer derived $\mathrm{Cd}\left(\mathrm{Cd}_{\mathrm{dff}}\right)$ in soil-wheat systems using a novel combination of enriched stable $\mathrm{Cd}$ isotope mass balances, sequential extractions and Bayesian isotope mixing models. We applied an enriched ${ }^{111} \mathrm{Cd}$ labeled mineral $\mathrm{P}$ fertilizer to arable soils from two long-term field trials with distinct soil properties (acidic and neutral soil $\mathrm{pH}$ ) on which we cultivated wheat in a pot trial. In the past decades, these soils have received distinct mineral P fertilizer application rates that were below or above the Swiss fertilization guidelines.

Soil and wheat $\mathrm{Cd}$ concentrations increased with increasing past mineral $\mathrm{P}$ fertilizer rates in the neutral but not in the acidic soil. In the acidic soil, secondary effects such as enhanced $\mathrm{Cd}$ outputs through increased wheat biomass may have outbalanced Cd soil inputs. Less than $2.3 \%$ of freshly applied $\mathrm{Cd}_{\mathrm{dff}}$ was taken up by the whole wheat plant while less than $0.3 \%$ of $\mathrm{Cd}_{\mathrm{dff}}$ was transported into the grains. Most of the freshly applied $\mathrm{Cd}_{\mathrm{dff}}$ remained in the soil and $>95 \%$ of $\mathrm{Cd}_{\mathrm{dff}}$ was partitioned into the easily mobilizable acetic acid soluble fraction (F1) and the potentially mobilizable reducible fraction (F2). Soil $\mathrm{pH}$ was the determining factor for the partitioning of $\mathrm{Cd}_{\mathrm{dff}}$ into $\mathrm{F} 1$ as highlighted by a recovery of about $40 \%$ of freshly applied $\mathrm{Cd}_{\mathrm{dff}}$ in $\mathrm{F} 1$ in the neutral $\mathrm{pH}$ soil compared to about $60 \%$ in the strongly acidic soil. Isotope mixing models showed that F1 was the predominant $\mathrm{Cd}$ source for wheat on both soils and contributed over $80 \%$ of $\mathrm{Cd}$ that was taken up by wheat. By tracing the fate of $\mathrm{Cd}_{\mathrm{dff}}$ in entire soil-plant systems using different isotope source tracing approaches, we showed that the majority of $\mathrm{Cd}_{\mathrm{dff}}$ remains mobile and will be potentially plant available in the subsequent crop cycle. At the conference, these results will be used to discuss possibilities and limits of enriched stable isotope tracers to improve risk assessment of $\mathrm{Cd}$ and potential other trace metals in agriculture. 